\title{
REVIEW
}

\section{Mortality among US and UK veterans of the Persian Gulf War: a review}

\author{
H K Kang, T A Bullman, G J Macfarlane, G C Gray
}

Occup Environ Med 2002;59:794-799

Mortality data on Gulf War veterans was reviewed as a means of evaluating the long term consequences of the war. Studies were located from searches of Medline, Proceedings of the Conference on Federally Sponsored Gulf War Veterans' Illnesses Research, Proceedings of the American Public Health Association Annual Meetings, Annual Reports to Congress, and personal contacts with knowledgeable investigators. Data on study design, methods, and results were obtained from published studies of both US and UK veterans who served in the Persian Gulf. The methodology and results of studies are summarised and evaluated. Additional research recommendations based on reviewed studies are presented. It is concluded that in both US and UK studies, mortality from external causes was higher, while mortality from all illnesses was lower among Gulf War veterans in comparison to those of non-Gulf War veterans. Increased mortality from external causes is consistent with patterns of postwar mortality observed in veterans of previous wars. Further follow up of Gulf War veterans and their controls is warranted for evaluating the mortality risk from diseases with longer latency periods.

See end of article for authors' affiliations

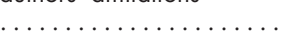

Correspondence to: Dr H K Kang, Environmental Epidemiology Service, Department of Veterans Affairs, 1120 20th Street NW Suite 950,

Washington, DC, 20036, USA; han.kang@

mail.va.gov

Accepted 14 May 2002
D uring a one year period between August 1990 and July 1991, the USA deployed close to 700000 troops to the Persian Gulf in response to Iraq's invasion of Kuwait. The air war against Iraq began in the middle of January 1991. Five days after the ground war began, Iraq capitulated and the war was over by 28 February 1991. In addition to the USA, over 30 other countries provided air, sea, or ground forces to coalition forces. The UK contributed the second largest number of troops from Western countries, approximately 53000 , to the coalition effort. The logistics build up included an estimated 110 ships, 2000 tanks, 2200 armed personnel carriers, 1800 fixed wing aircraft and 1700 helicopters. Despite the short duration of the war, troops deployed to the Gulf were exposed to natural and man made hazards of the war. A list of potentially harmful aetiological exposures has been evolving and the list now includes oil well fire smoke, chemical and biological warfare (CBW) agents, prophylactic agents against CBW, multiple vaccinations, depleted uranium, pesticides, and endemic infectious diseases. ${ }^{1-5}$
Within months of their return from the Gulf, a number of Gulf War veterans began to complain of various symptoms and illnesses. In response to increasing concern about the health of US Gulf War veterans, the Departments of Defense (DOD) and Veterans Affairs (VA) initiated an intensive health registry examination programme and sponsored numerous health studies. ${ }^{6-14}$ Studies on the health of UK Gulf War veterans were also commissioned by the Medical Research Council in the UK.

In parallel to the concern for ill health, there has been persistent suggestion that Gulf War veterans may have had a higher rate of postwar mortality than non-Gulf veterans, and that certain causes of death may have been especially increased. Excess numbers of deaths from cardiovascular disease and from malignant neoplasm have been suggested.

The purpose of this report is to review mortality data on Gulf War veterans as a means of evaluating the long term health consequences of their service in the Gulf War. To identify research on the mortality of Gulf War veterans, a number of sources were queried: Medline, Proceedings of the Conference on Federally Sponsored Gulf War Veterans' Illnesses Research, Proceedings of the Annual American Public Health Association Meetings, Annual Reports to Congress, and personal contacts with knowledgeable investigators.

Studies may be divided into two broad categories: (1) mortality experience of active duty military personnel during the war (table 1); and (2) postwar mortality experience of all Gulf War veterans, whether they were on active duty or separated from the military since the war (table 2).

\section{MORTALITY DURING THE WAR}

Helmkamp published a study describing battle and non-battle fatalities during the six week combat phase of Operations Desert Shield and Desert Storm, 17 January 1991 through 28 February 1991. ${ }^{1}$ The source of information for troop strength by branch of service in January and February 1991 was the Department of Defense Joint Staff Manpower and Personnel Office. The mortality data were obtained from the automated Worldwide Casualty System maintained and operated by DOD. The Report of Casualty (DD1300) is the official military record of death for all military personnel who die while on active duty.

Abbreviations: $C B W$, chemical and biological warfare; MVA, motor vehicle accident; RR, rate ratio; SMR, standardised mortality ratio 
Table 1 Published US Gulf War veteran mortality during the conflict period

\begin{tabular}{llll}
\hline $\begin{array}{l}\text { Authors } \\
\text { Year }\end{array}$ & $\begin{array}{l}\text { Study design } \\
\text { Country }\end{array}$ & Description & Results \\
\hline $\begin{array}{l}\text { Helmkemp } \\
1994\end{array}$ & $\begin{array}{l}\text { Cohort } \\
\text { USA }\end{array}$ & $\begin{array}{l}\text { A study of fatal battle and non-battle causalities from } \\
17 / 1 / 91 \text { to } 28 / 2 / 91 \text { among approximately } 540000\end{array}$ & $\begin{array}{l}154 \text { killed in battle including } 35 \text { from a friendly fire; } 65 \\
\text { died from non-battle causes including } 55 \text { from accidents } \\
\text { active duty US military personnel deployed to the } \\
\text { and } 6 \text { from illness }\end{array}$ \\
Persian Gulf & $\begin{array}{l}\text { A study of cause specific mortality rates among } \\
688702 \text { active duty personnel deployed to the Persian } \\
\text { Gulf from } 1 / 8 / 90 \text { to } 31 / 7 / 91 \text { and all other troops } \\
\text { serving elsewhere during the same period }\end{array}$ & $\begin{array}{l}\text { The risks of death from injuries (SMR } 118,95 \% \text { and unintentional injuries (SMR } 154,95 \% \text { to } 177 \text { ) were significantly higher among Gulf } \\
\text { veterans }\end{array}$ \\
\hline
\end{tabular}

A total of 219 troops (212 men and seven women) were killed during the six week period. Of these, 154 ( 148 men and six women) were battlefield casualties and 65 non-battlefield casualties. Fifty five of the 65 non-battle deaths resulted from accidental injuries; other causes included six illnesses, two suicides, and one homicide. Battle and non-battle casualty rates were the lowest experienced by the USA in any major conflict in the twentieth century.

Writer et al expanded the earlier mortality study of active duty Gulf War veterans to include a comparison group of troops serving elsewhere during the war and a longer observation period from 1 August 1990 to 31 July $1991 . .^{15}$ The personnel data were obtained from the Defense Manpower Data Center (DMDC), which included all persons on active duty on 1 August 1990 and all persons who entered active service, including activated Reserve and National Guard through 31 July 1991. During the period from l August 1990 to 31 July 1991, a total of 2590193 persons served on active duty and 688702 were deployed to the Persian Gulf. Mortality data were obtained from the previously described DD1300.

Cause specific crude mortality rates were calculated for Gulf War veterans and non-Gulf War veterans. To estimate the number of expected deaths among Gulf War veterans, age specific mortality rates among non-Gulf veterans were applied to the Gulf War veterans. The ratio of observed to expected deaths multiplied by 100 , or standardised mortality ratios (SMRs) were calculated as summary statistics comparing the two groups. Of the 372 deaths among the Gulf War veterans, 147 were battle related, 194 were non-battlefield injuries, and 30 resulted from illness.

Writer et al reported no evidence of excess deaths as a result of rapidly fatal illnesses among Gulf War veterans (SMR 93.9,
95\% CI 63.3 to 134.2 ), while deaths owing to all injury (SMR $117.8,95 \%$ CI 101.2 to 134.3 ) and its subset of unintentional injury (SMR 154.3, 95\% CI 132 to 177) were significantly increased among Gulf veterans. An anticipated high mortality rate from a rapidly fatal illness, had there been a widespread exposure to a chemical or biological warfare agent such as sarin gas or anthrax, was not apparent among Gulf War veterans in this study.

\section{POSTWAR MORTALITY STUDIES}

Kang and Bullman conducted a cause specific postwar mortality study of 695516 Gulf War veterans and 746291 non-Gulf veterans. ${ }^{16}$ All military personnel identified by DMDC as having been deployed in the Persian Gulf were selected as a study cohort. Approximately half of all personnel on active duty, in the National Guard, and in the military reserve during the war but who did not go to the Persian Gulf were selected as a control cohort. Available demographic and military service data included the veteran's date of birth, race, sex military rank, branch of service, deployment data, and the type of unit (active, reserve, or National Guard). Vital status follow up for each Gulf War veteran began the date he or she left the Persian Gulf theatre. Follow up for controls began on l May 1991. Follow up for both groups ended on day of death or 30 September 1993, whichever came first. The cut off of 30 September 1993 was used, as vital status data were incomplete after that date at the time of the study. Vital status was determined using databases of VA and the Social Security Administration (SSA). The VA database known as Beneficiary Identification and Records Locator Subsystem (BIRLS) is a computerised file of veterans who are eligible for benefits,

Table 2 Published US Gulf War veteran mortality during the postwar period

\begin{tabular}{|c|c|c|c|}
\hline $\begin{array}{l}\text { Authors } \\
\text { Year }\end{array}$ & $\begin{array}{l}\text { Study design } \\
\text { Country }\end{array}$ & Description & Results \\
\hline $\begin{array}{l}\text { Kang and Bullman } \\
1996\end{array}$ & $\begin{array}{l}\text { Cohort } \\
\text { USA }\end{array}$ & $\begin{array}{l}\text { A study of postwar mortality through } 30 / 9 / 93 \\
\text { among } 695516 \text { Gulf veterans and } 746291 \text { other } \\
\text { veterans }\end{array}$ & $\begin{array}{l}\text { Gulf veterans had significant excesses of death from } \\
\text { all external causes (RR } 1.17,95 \% \mathrm{Cl} 1.08 \text { to } 1.27 \text { ) } \\
\text { and from motor vehicle accidents (RR } 1.31,95 \% \mathrm{Cl} \\
1.14 \text { to } 1.49 \text { ), while mortality from disease related } \\
\text { causes was lower (RR } 0.88,95 \% \mathrm{Cl} 0.77 \text { to } 1.02 \text { ) }\end{array}$ \\
\hline $\begin{array}{l}\text { Kang et al } \\
1997\end{array}$ & $\begin{array}{l}\text { Nested } \\
\text { case-control }\end{array}$ & $\begin{array}{l}549 \text { male Gulf veterans and } 398 \text { male non-Gulf } \\
\text { veterans who died from MVA were compared on host } \\
\text { and external factors (demographics, military } \\
\text { characteristics, vehicle type, nature of accidents, etc) } \\
\text { using data obtained from the National Highway } \\
\text { Transportation Safety Administration }\end{array}$ & $\begin{array}{l}\text { Gulf veterans died from MVA accidents less often } \\
\text { used seat belt, or wore motorcycle helmets; more } \\
\text { often speeding, collision with fixed objects, head-on } \\
\text { collisions, alcohol involved, or died at scene of the } \\
\text { accidents }\end{array}$ \\
\hline $\begin{array}{l}\text { Macfarlane et al } \\
2000\end{array}$ & $\begin{array}{l}\text { Cohort } \\
\text { UK }\end{array}$ & $\begin{array}{l}\text { A study of postwar mortality from } 1 / 4 / 91 \text { to } \\
31 / 3 / 99 \text { among } 53462 \text { Gulf veterans and an equal } \\
\text { number of non-Gulf veterans }\end{array}$ & $\begin{array}{l}\text { Mortality from external causes was higher (MRR } 1.18 \text {, } \\
95 \% \mathrm{Cl} 0.98 \text { to } 1.42 \text { ) while mortality from disease } \\
\text { related causes was lower in the Gulf cohort }(0.87 \text {, } \\
0.67 \text { to } 1.11 \text { ). }\end{array}$ \\
\hline $\begin{array}{l}\text { Kang and Bullman } \\
2001\end{array}$ & $\begin{array}{l}\text { Cohort } \\
\text { USA }\end{array}$ & $\begin{array}{l}\text { Further update of the US Gulf veteran mortality study } \\
\text { through } 31 / 12 / 97 \text {. A total of } 10424 \text { deaths in } 61 / 2 \\
\text { year postwar period were analysed by their } \\
\text { deployment status. For Gulf veterans, the mortality risk } \\
\text { was also evaluated for the likelihood of exposure to } \\
\text { nerve gas from Khamisiyah incidents }\end{array}$ & $\begin{array}{l}\text { Over the entire } 61 / 2 \text { year period, the risk of deaths } \\
\text { due to MVA was still higher; however, the risk had } \\
\text { decreased steadily over time. The risk of death due to } \\
\text { disease related causes remained at or below } \\
\text { expected values }\end{array}$ \\
\hline
\end{tabular}


including death benefits. The Death Master File is a file of deaths reported to the Social Security Administration. A recent study indicated that BIRLS and SSA collectively recorded $96 \%$ of all Vietnam era veteran deaths.

Death certificates were requested from the VA regional office (VARO) or Federal Record Center (FRC) identified in BIRLS as the location of the veteran's claim folder. For those death certificates not available from a VARO or FRC, the National Death Index (NDI) was used. Since 1979, state vital statistic offices have reported all deaths, including cause of death data, to the National Center for Health Statistics, which maintains the NDI database. Causes of death were coded by a qualified nosologist who used the International Classification of Disease, 9th revision (ICD-9), ${ }^{17}$ without knowing the subject's deployment status.

The relative frequency of the overall as well as cause specific mortality of Gulf veterans and non-Gulf veterans were compared using crude rate ratios (RRs), expressed as the rate observed among Gulf veterans to the rate observed among non-Gulf veterans. Gulf veterans had a slight excess of overall mortality (RR 1.08) compared to non-Gulf veterans. This excess was due primarily to external causes (RR 1.29). Comparing male and female Gulf veterans separately to their non-Gulf counterparts, both males and females had an excess of overall mortality (RR 1.10 and 1.41 , respectively). This excess was due primarily to an excess of deaths owing to external causes among both male and female Gulf veterans (RR 1.26 and 1.95 , respectively).

The next analysis used the Cox proportional hazards model to calculate adjusted rate ratios, as estimates of relative risk. The Cox model accounts for possible confounding and effect modification by selected covariates related to the risk of dying from a specific cause, according to the time since the veteran's entry into the cohort. ${ }^{18}$ Covariates used in the model included Persian Gulf service (yes/no), age at entry to follow up, race, sex, service branch, and type of military unit. Rate ratios whose 95\% CI did not include 1.00 were considered statistically significant. Entering all Gulf and non-Gulf veterans into the model, Gulf veterans had an excess of overall mortality (RR $1.09,95 \%$ CI 1.01 to 1.16 ). This excess was a result of external causes of death (RR 1.17, 95\% CI 1.08 to 1.27). The risk of disease related deaths and specifically infectious diseases were smaller among Gulf veterans than non-Gulf veterans (RR $0.88,95 \%$ CI 0.77 to 1.02 and RR 0.21 , $95 \%$ CI 0.11 to 0.43 , respectively). This analysis was also done separately for male and female veterans. Compared to their non-Gulf counterparts, both male and female Gulf veterans had an excess of overall mortality (RR 1.09, 95\% CI 1.01 to 1.18 and RR 1.32, 95\% CI 0.95 to 1.83, respectively). Again this excess was a result of external causes of death rather than disease related deaths. Compared to their non-Gulf counterparts, both male and female Gulf veterans had statistically significant increased risk of external causes of deaths. Female Gulf veterans had a larger increased risk than their male counterparts (RR 1.78 and 1.17, respectively).

Finally, the mortality of Gulf veterans and non-Gulf veterans was compared separately to that of the US population, with adjustment for age, gender, race, and year of death. ${ }^{19}$ The results are presented as SMRs, expressing the ratio of observed deaths among veterans to the expected numbers of deaths in the general population. Any SMR whose 95\% CI did not include 1.0 was considered to be statistically significant. The overall mortality of both Gulf and non-Gulf veterans was less than half that expected based on the general population ( SMR 0.44, 95\% CI 0.42 to 0.47 and SMR 0.38, 95\% CI 0.36 to 0.40 , respectively).

While troops sent to the Persian Gulf before 1 March 1991 would have been subjected to many of the potential risk factors associated with service in the Persian Gulf (pyridostigmine bromide pills, anthrax vaccine, Scud missile attacks, combat stress, etc), those deployed after that date when the war ended would not have been similarly exposed. Comparing these two groups of Gulf War veterans, there was no difference in cause specific mortality.

Kang and Bullman further extended the follow up period to 31 December 1997 for these veteran cohorts, adding an additional 4 years 3 months of observation. ${ }^{20}$ For Gulf War veterans, mortality risk was also assessed relative to the likelihood of exposure to nerve gas plumes originating from the demolition of munitions containing nerve gas stored at Khamisiyah, Iraq. ${ }^{21-23}$

Over the entire 6 $1 \frac{1}{2}$ years of follow up, May 1991 to December 1997, the risk of deaths caused by motor vehicle accidents was still significantly higher among Gulf veterans than for non-Gulf veterans (male veterans: adjusted rate ratio 1.19, $95 \%$ CI, 1.09 to 1.30 ; female veterans: adjusted rate ratio 1.63 , $95 \%$ CI, 1.09 to 2.45$)$. However, during the same $6 \frac{1}{2} 2$ year period, the risk of death from motor vehicle accidents (MVA) has decreased steadily over time. The risk of death owing to disease related causes remained lower or about the level expected among Gulf War veterans in comparison to non-Gulf veterans (males: adjusted rate ratio $0.83,95 \%$ CI 0.78 to 0.89 ; females: adjusted rate ratio $1.02,95 \%$ CI 0.79 to 1.33 ). The deficit from death caused by infectious diseases contributed significantly to the lower mortality from disease related causes. Fifty seven per cent of deaths caused by infectious diseases among Gulf War veterans and $82 \%$ of deaths caused by infectious diseases among non-Gulf veterans were related to human immunodeficiency virus (HIV) infection (ICD-9, 042). Comparing the mortality rate of 48281 Gulf War veterans who were potentially exposed to nerve gas to that of 573621 other Gulf War veterans who were not likely to have been exposed, there was no statistically significant increased risk in any cause specific mortality.

Figure 1 illustrates changes in relative mortality over time by four follow up periods of approximately 20 months each for selected causes. For Gulf War veterans, the risk of death from MVAs has decreased steadily over time, from a rate ratio of 1.32 (95\% CI 1.13 to 1.53 ) in the first follow up period to a rate ratio of 1.00 (95\% CI 0.82 to 1.22 ) in the last follow up period. The $\chi^{2}(7.53)$ indicated a significant $(\mathrm{p}=0.0061$, two sided $)$ decreasing trend in the risk of MVA death with increasing time since the Gulf War among Gulf veterans compared with non-Gulf veterans. Risk of mortality owing to disease related causes among Gulf veterans in comparison with non-Gulf veterans has steadily increased over the last three follow up periods. In the most recent follow up period, the risks of mortality from natural causes were almost identical in the two veterans cohorts.

Macfarlane et al published a postwar mortality study of UK Gulf War veterans. ${ }^{24}$ All 53462 veterans who served in the Gulf at some time between September 1990 and June 1991 were compared to an equal number of veterans who were in the military on 1 January 1991 but did not serve in the Gulf. Selection was random but stratified to match the Gulf cohort on age (within five year age group), gender, service, fitness for active service, and rank.

Study subjects were identified by the UK Ministry of Defense, and the ministry provided for each veteran information on age as of 1 January 1991, gender, service branch, rank, and date of joining and leaving the military. Vital status was followed from 1 April 1991 to 31 March 1999 using the National Health Service (NHS) Central Registry, which contained an entry for everyone who had been registered with a general medical practitioner in the UK since 1991. If a veteran was registered as having died in the UK, the Office for National Statistics (ONS) provided information on the date and cause of death recorded on the death certificate. Causes of death were coded using the ICD-9 codes without knowing the veteran's deployment status. When death occurred in service overseas, the information on cause of death was obtained either from the Defense Analytical Service Agency or, where 


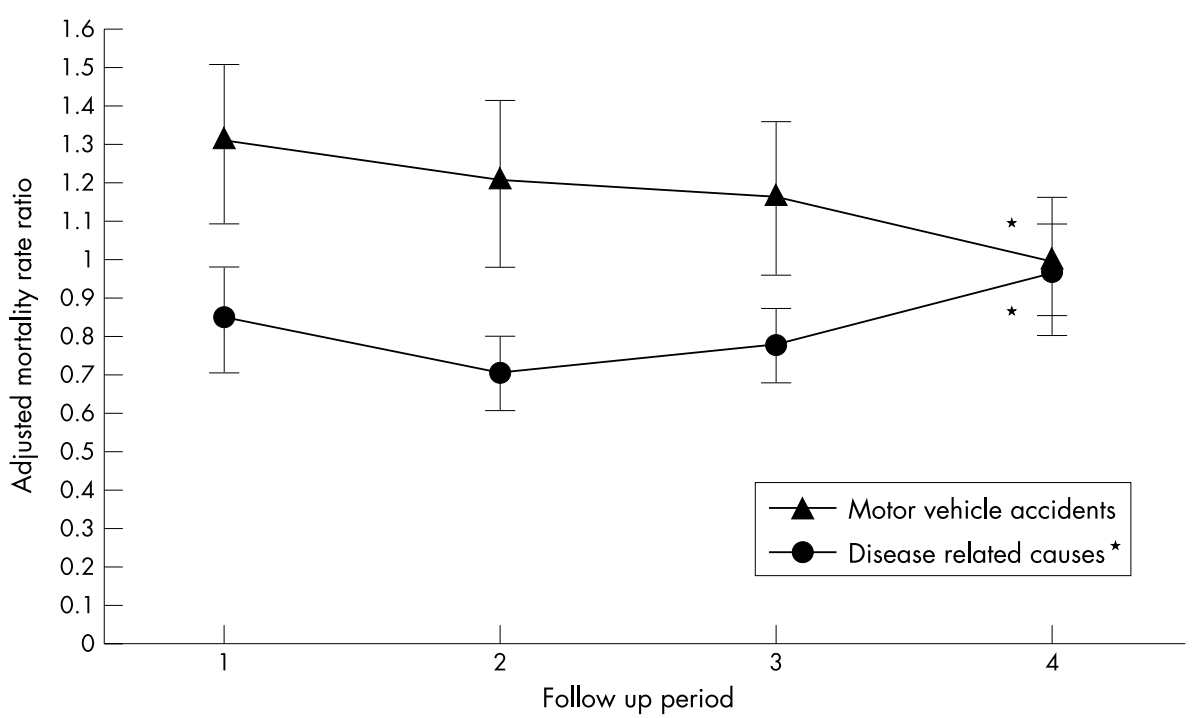

Figure 1 Relative mortality over time by four follow up periods between Gulf War veterans and non-Gulf veteran peers. Follow up 1: entry to 31 December 1992; follow up 2: 1 January 1993 to 31 August 1994; follow up 3: 1 September 1994 to 30 April 1996; follow up 4: 1 May 1996 to 31 December 1997.

available, from military sources in the country of death; cause of death was then coded by the ONS.

A mortality rate for each cause of death was calculated based on the number of deaths and the person-years at risk, and subsequently a mortality rate ratio with $95 \%$ CI for comparison between Gulf War veterans and non-Gulf veterans. As with US Gulf War veterans, mortality from external causes was higher in the UK Gulf War veteran cohort (mortality rate ratio $1.18,95 \%$ CI 0.98 to 1.42 ) while mortality from disease related causes was lower (mortality rate ratio $0.87,95 \%$ CI 0.67 to 1.11 ). The higher mortality rate from external causes was primarily a result of a higher number of deaths from MVAs, air/space accidents, or deaths associated with submersion, suffocation, or foreign bodies. There was no excess of deaths in the Gulf War veteran cohort recorded either as suicide or from injury from unknown cause.

\section{POTENTIAL RISK FACTORS FOR THE EXCESS DEATHS FROM MOTOR VEHICLE ACCIDENTS}

In an effort to evaluate the possible reasons for the excess deaths caused by MVA, Kang et al analysed data from 549 Gulf War veterans and 398 non-Gulf veterans who died from MVAs (ICD-9, E810-E825). ${ }^{25}$ Gulf and non-Gulf veterans were compared on numerous host and external factors including age, race, gender, marital status, driver status (driver versus passenger), vehicle type, speed, alcohol and drug measures, seat belt use, nature of collision (fixed object versus moving vehicle). Data for the evaluation were obtained from the mortality study and the Fatal Accident Reporting System (FARS), a standardised nationwide database maintained by the National Highway Transportation Safety Administration of the Department of Transportation. The FARS collects information on over 100 variables from police crash reports, emergency medical transport records, and medical examiner/ coroner/autopsy reports.

Of the 947 veterans identified as having died from MVA, $92 \%$ were on the FARS. Those who were not on the FARS were veterans who died overseas. Gulf veterans who died from MVA accidents less often used seat belts, wore motorcycle helmets, or made crash avoidance manoeuvres; and more often were speeding, had alcohol involved, had single vehicle crash, collisions with fixed objects, rollovers, ejections, and previous driving under the influence convictions. More Gulf veterans died at the scene of the accident or within one hour of medical attention. This descriptive pattern lends support to specu- lation that Gulf veterans being the survivors of war would perceive the degree of risk in any given situation differently from other non-war veterans and may therefore engage in more risk taking behaviour.

\section{METHODOLOGICAL ISSUES}

A study of mortality experience in US Gulf War veterans is considerably less problematic than a study of their morbidity. Unlike studies of other veteran groups, Gulf War veterans and non-Gulf veterans were fully characterised and enumerated by the Department of Defense. The sources used for vital status in the VA study should ensure fairly complete vital status ascertainment for both groups of veterans. ${ }^{26}$ In the first VA mortality study, it was determined that vital status was ascertained at an estimated rate of $89 \%$ (95\% CI 83-97\%) with no significant differences between Gulf War and non-Gulf War veterans. ${ }^{16}$ Cause of death was obtained for equally high percentages of both groups of veterans, 93.7\% of Gulf veterans, and $93.4 \%$ of non-Gulf veterans. For a more complete ascertainment of vital status of veterans, one could use the National Death Index maintained by the National Center for Health Statistics, but cost likely outweighs the gain.

Another strength of the VA mortality study was substantial statistical power to detect small to moderate increased risks of cause specific mortality. ${ }^{16}$ Sampling errors should also be reduced as all Gulf War veterans were used as the study group and almost half of all veterans who did not go to the Persian Gulf were used as a comparison group. ${ }^{27}$

A potential limitation of the VA study is that some of the non-Gulf veterans may not have been as healthy as those who were sent to the Persian Gulf as indicated by the excess deaths from HIV infection among non-Gulf veterans. Non-Gulf veterans may have included individuals who were recovering from surgery or had ailments serious enough to preclude them from being deployed but not serious enough to require their dismissal from the military. To evaluate the magnitude of this potential selection bias, Kang and Bullman compared the mortality of a group of 106840 non-Gulf Reservists and National Guard veterans who were activated and deployed to locations other than the Persian Gulf to that of 115478 Reserve and National Guard members who were not deployed at all. ${ }^{27}$ Again using the Cox proportional hazards models, there was no difference in either overall mortality or cause specific mortality between the two groups, although the adjusted rate ratio for 
infectious and parasitic disease (ICD 001-139) was 0.43 (95\% CI 0.11 to 1.62 ). If there had been a significant selection bias, those deployed would have had a significantly lower risk of cause specific mortality than those who were not deployed. Gray et al also reported, on the basis of history of prewar hospitalisation rates among Gulf and non-Gulf veterans, that the effect of the possible selection bias was transient and largely resolved by the conclusion of the war. ${ }^{28}$ They stated that military personnel, in general, are healthy and without serious chronic conditions. If they develop a chronic disease that causes a sustained reduction in their ability to perform their military duties, they are eventually separated from military service. We believe the effect of this potential selection bias would be very limited and could not have accounted for the findings. It should be noted, however, that in the UK study this potential selected bias is not an issue as the two cohorts were matched on fitness for active service.

Another potential limitation is the reliance on death certificates rather than medical records for cause of death data. While death certificates are reliable sources for vital status ascertainment, their accuracy in recording cause of death may be variable..$^{29}$ However, the agreement between medical records and death certificates has been reported to be good for external causes of death. ${ }^{31}$ One additional limitation is the lack of data on non-military service related characteristics/ behaviours, for example, excessive alcohol consumption and smoking, that could be risk factors for adverse health outcomes. However, such factors should be present in similar proportions in both Gulf War and non-Gulf veterans, as both joined the military prior to the Gulf War, and in almost all instances deployment to the Persian Gulf area was not voluntary.

\section{DISCUSSION}

Over the entire $6^{1 / 2}$ year follow up period, US Gulf War veterans, both males and females, were at a higher risk of deaths from accidents, especially MVA. However, this risk has diminished as length of follow up has increased. By the sixth year of follow up (May 1996 to December 1997), the relative mortality caused by MVAs had fallen from 1.32 to 1.0. This observation was consistent with a mortality study of Vietnam veterans in which the excess mortality as a result of MVAs was most pronounced in the first five years after Vietnam service, decreasing in the sixth year of follow up to the levels found in the non-Vietnam group. ${ }^{31}$ There was an indication of increased relative mortality owing to disease related causes with increasing time since the Gulf War, although the rate ratios remained below 1.0 at all times. This could be explained by the excess deaths related to HIV infection among non-Gulf veterans. Troops who were HIV positive during the war were not deployed to the Persian Gulf. If most of them developed AIDS and died since the war, and if the relative risk from other natural causes remained unchanged, the rate ratio for the natural causes would have risen steadily towards 1.0.

The VA study also found that both US Gulf and non-Gulf veterans were healthier than the US general population. This finding is consistent with the "healthy soldier effect", that has been reported in other studies of veteran groups. ${ }^{32-35}$ Because of the initial screening for military service, requirements to maintain certain levels of physical fitness, and better access to medical services during and after military service, military cohorts typically are healthier than their comparable nonmilitary civilian counterparts. A recent study of veterans who were on active duty in 1986 reported that the mortality of the veterans was half that of a civilian comparison group. ${ }^{33}$

The underlying reasons for the increased risk of traumatic deaths among Gulf veterans are still not fully understood. One possible explanation is that they may have engaged in more risk taking behaviour. A population-based survey of 30000 Gulf War era veterans indicated that since the war, Gulf War veterans were more involved with a serious accident, injury, or illness than non-Gulf veterans. ${ }^{36}{ }^{37}$ Furthermore, a smaller portion of Gulf War veterans who died from MVAs used seat belts at the time of the fatal accident than non-Gulf veterans who died from MVAs. ${ }^{25}$ Another possible explanation is that those in combat may be at increased risk for post-traumatic stress disorder, which in turn contributes to the excess number of deaths caused by trauma. ${ }^{38}$

\section{CONCLUSION AND FUTURE RESEARCH NEEDS}

Since the Gulf War, both US and UK Gulf War veterans have consistently reported a wide variety of health problems. Although these health problems were debilitating, they did not manifest in a significantly higher mortality from disease related causes, including cancers and infectious diseases. Both US and UK Gulf veterans did have excess deaths from accidents, especially MVAs. The US and UK study results are remarkably similar despite the fact that they studied two different Gulf War populations using different study methods. Among US veterans, the risk was greater during the earlier postwar years; the risk decreased over time to the level that was expected in non-Gulf veterans. The underlying reasons for the excess of deaths caused by accidents are not known at this time. To what extent the excess of deaths is related to host behaviour factors warrants further study. In addition, a parallel study of veterans of the more recent conflict in Bosnia and Kosovo would be of interest to determine whether similarly increased rates of deaths for external causes are to be found among these veterans.

\section{Authors' affiliations}

H K Kang, T A Bullman, The Environmental Epidemiology Service, Department of Veterans Affairs, Washington, DC, USA

G J Macfarlane, School of Epidemiology and Health Sciences, University of Manchester, Manchester, UK

G C Gray, College of Public Health, University of lowa, lowa City, USA

Support: The Medical Research Service, Office of Research and Development, Department of Veterans Affairs

\section{REFERENCES}

1 Helmkamp JC. United States military casualty comparisons during the Persian Gulf War. J Occup Med 1994;36:609-15.

2 Presidential Advisory Committee on Gulf War Veterans' Illnesses. Final report. Washington, DC: US Government Printing Office, December 1996 (ISBN 0-16-048942-3)

3 National Institutes of Health Technology Assessment Workshop Panel. The Persian Gulf experience and health. JAMA 1994;272:391-5.

4 Institute of Medicine. Health consequences of service during the Persian Gulf War: Recommendations for research and information systems. Washington, DC: National Academy Press, 1996

5 Institute of Medicine. Gulf War veterans. Measuring health. Committee on Measuring the Health of Gulf War Veterans. Washington, DC: National Academy Press, 1999.

6 Murphy FM, Kang HK, Dalager N, et al. The health status of Gulf War veterans: lessons learned from the Department of Veterans Affairs health registry. Milit Med 1999;164:327-31.

7 Joseph SC, and the Comprehensive Clinical Evaluation Program Team. A comprehensive clinical evaluation of 20,000 Persian Gulf War veterans. Milit Med 1997;162:149-55.

8 Gray GC, Hawksworth AW, Smith TC, et al. Gulf War veterans' health registries. Who is most likely to seek evaluation? Am J Epidemiol 1998;148:343-9.

9 Department of Veterans Affairs. Annual report to Congress. The Research Working Group of the Persian Gulf Veterans Coordinating Board. June 1999.

10 Cowan DN, DeFraites RF, Gray GC, et al. A record based evaluation of the risk of birth defects among children of Gulf War veterans. N Engl J Med 1997;336: 1650-6.

11 The lowa Persian Gulf Study Group. Self-reported illness and health status among Gulf War veterans. JAMA 1997;277:238-45

12 Gray GC, Kaiser KS, Hawksworth AW, et al. Increased postwa symptoms and psychological morbidity among U.S. Navy Gulf War veterans. Am J Trop Med Hyg 1999;60:758-66.

13 Fukuda K, Nisenbaum R, Stewart G, et al. Chronic multisymptom illness affecting Air Force veterans of the Gulf war. JAMA 1998;280:981-8.

14 Gray GC, Coate BD, Anderson CM, et al. The postwar hospitalization experience of U.S. Veterans of the Persian Gulf War. N Engl J Med 1996;335: 1505-13. 
15 Writer JV, DeFrautes RF, Brundage JF. Comparative mortality among U.S. military personnel in the Persian Gulf region and worldwide during Operations Desert Shield and Desert Storm. JAMA 1996;275: 118-21.

16 Kang HK, Bullman TA. Mortality among U.S. Veterans of the Persian Gulf War. N Engl J Med 1996;335:1498-504.

17 International Classification of Diseases. Manual of the international statistical classification of diseases, injuries, and causes of death, 9th rev, vol 1. Geneva: World Health Organisation, 1977

18 SAS/STAT software. The PHREG procedure, version 6. Technical report. Cary, NC: SAS Institute, 1991:217.

19 Boice J, Pickle L, Thomas TL, et al. O/E system: observed versus expected events: users guide, version 3.8. Bethesda, MD: National Cancer Institute, 1991.

20 Kang HK, Bullman TA. Mortality among U.S. veterans of the Gulf War: 7-year follow-up. Am J Epidemiol 2001;154:399-405.

21 Rostker B. U.S. demolition operations at the Khamisiyah ammunition storage point. Washington, DC: Department of Defense, 14 April 1997.

22 Persian Gulf War Illnesses Task Force. Khamisiyah: a historical perspective on related intelligence. Washington, DC: Central Intelligence Agency, 1997

23 Walpole RD, Rostker B. Modeling the chemical warfare agent release at the Khamisiyah pit. Washington, DC: Department of Defense, 4 September 1997

24 Macfarlane GJ, Thomas E, Cherry N. Mortality amongst United Kingdom Gulf War veterans. Lancet 2000;356:17-21.

25 Kang HK, Magee CA, Bullman TA. Analysis of potential risk factors for the excess accidental deaths among Persian Gulf veterans. Presented at the 125th American Public Health Association Meeting, 11 November 1997, Indiana, IN

26 Page WF, Mahan CM, Kang HK. Vital status ascertainment through the files of the Department of Veterans Affairs and the Social Security Administration. Ann Epidemiol 1996;6:102-9.
27 Kang HK, Bullman TA. Counterpoint: negligible "healthy-warrior effect" on Gulf War veterans' mortality. Am J Epidemiol 1998;148:324-5.

28 Gray GC, Knoke JD, Berg SW, et al. Counterpoint: responding to suppositions and misunderstandings. Am J Epidemiol 1998;148:32833.

29 Engel LW, Struachen JA, Chiazze L, et al. Accuracy of death certificates in an autopsied population with specific attention to malignant neoplasms and vascular diseases. Am J Epidemiol 1980;111:99-112.

30 Percy C, Stanek E, Gloeskler L. Accuracy of cancer death certificates and its effects on cancer mortality statistics. Am J Public Health $1981 ; 71: 242-50$.

31 The Centers for Disease Control. Vietnam experience study. Post service mortality among Vietnam veterans. JAMA 1987;257:790-5.

32 Seltzer CC, Jablon S. Effects of selection on mortality. Am J Epidemio 1974;100:367-72.

33 Rothberg JM, Bartone PT, Holloway HC, et al. Life and death in the US Army: in corpore sano. JAMA 1990;264:2241-4.

34 Thomas TL, Kang HK, Dalager NA. Mortality among women Vietnam veterans, 1973-1987. Am J Epidemiol 1991;134:973-80.

35 Watanabe KK, Kang HK. Military service in Vietnam and the risk of death from trauma and selected cancer. Ann Epidemiol 1995;5:407-12.

36 Kang HK. National Health Survey of Gulf War Era Veterans and Their Families. Abstract. Conference on Federally Sponsored Gulf War Veterans' Illnesses Research. Pentagon City, VA, 17-19 June 1998.

37 Kang HK, Mahan CM, Lee KY, et al. Illnesses among United States veterans of the Gulf War: a population-based survey of 30,000 veterans. J Occup Environ Med 2000;42:491-501.

38 Bullman TA, Kang HK. Posttraumatic stress disorder and the risk of traumatic deaths among Vietnam veterans. J Nerv Ment Dis $1994 ; 182: 604-10$.

\section{OEM web submission and review system}

I am pleased to inform authors and reviewers of the new online submission and review system at OEM. Developed by Highwire Press (CA, USA), Bench $>$ Press is a fully integrated electronic system which uses the internet to allow rapid and efficient submission of manuscripts. It also allows the peer review process to be conducted entirely online. The main aim is to speed up the frequently frustrating progress from submission to publication.

Authors can submit their manuscript in any standard word processing software. Standard graphic formats accepted include: .jpg, .tiff, .gif, eps, etc. (Please note: multi page powerpoint files are not accepted by the BM Publishing Group.) The text and graphic files are automatically converted to PDF for ease of distribution and reviewing purposes. Authors are asked to approve their submission before it formally enters the reviewing process. On approval, the submission is passed to the editor and/or reviewers via the web. All transactions are secure.

To access the system click on "SUBMIT YOUR MANUSCRIPT HERE" on the OEM homepage: http://www.occenvmed.com, or you can access the submission site directly at http://submitoem.bmijournals.com.

We are very excited with this new development and would encourage authors and reviewers to use the system where possible. It really is simple to use and should greatly improve on the current peer review process. Full instructions can be found on Bench>Press http://submitoem.bmijournals.com and OEM online at http://www.occenvmed.com. Please contact Natalie Davies, Project Manager, ndavies@bmigroup.com.

Anne Cockcroft

Editor, OEM 